\title{
Abordagens teóricas no campo de política pública no Brasil e no exterior: do fato à complexidade
}

\author{
Marta Ferreira Santos Farah
}

Fundação Getulio Vargas (FGV)

Análise da trajetória do campo de política pública no Brasil e de seus principais desafios, a partir de um de seus subcampos, o de estudos de políticas públicas. $\mathrm{O}$ artigo considera a vertente de estudos que se desenvolveu com foco no processo. Após apresentar as principais teorias de política pública, analisa-se a trajetória dos estudos de políticas no Brasil. $\mathrm{O}$ artigo destaca, nas teorias contemporâneas, a incorporação da complexidade e da presença de atores não estatais; o deslocamento dos estudos do processo decisório (da formulação) para outras "etapas" do processo; e o reconhecimento da importância de instituições, da política e de ideias e valores na determinação da ação estatal. Mostra ainda como, na expansão recente da produção nacional sobre políticas, apesar da tendência à dispersão e à fragmentação, foram incorporadas abordagens teóricas contemporâneas. E destaca, dentre os desafios, fatores do ambiente político-institucional que podem comprometer a institucionalização do campo.

Palavras-chave: políticas públicas - Brasil, institucionalização, revisão de literatura

[Artigo recebido em 3 de abril de 2018. Aprovado em 9 de novembro de 2018.] 
Enfoques teóricos en el campo de política pública en Brasil y en el exterior: de hecho a la complejidad

Análisis de la trayectoria del campo de política pública en Brasil y de sus principales desafíos, a partir de uno de sus subcampos, el de estudios de políticas públicas. El artículo considera la vertiente de estudios que se desarrolló con foco en el proceso. Después de presentar las principales teorías de política pública, se analiza la trayectoria de los estudios de políticas en Brasil. El artículo destaca, en las teorías contemporáneas, la incorporación de la complejidad y de la presencia de actores no estatales; el desplazamiento de los estudios del proceso decisorio (de la formulación) a otras "etapas" del proceso y el reconocimiento de la importancia de instituciones, de la política y de ideas y valores en la determinación de la acción estatal. También muestra cómo, en la reciente expansión de la producción nacional sobre políticas, en que pese la tendencia a la dispersión y a la fragmentación, se ha producido la incorporación de los enfoques teóricos contemporáneos. Y destaca, entre los desafíos, factores del ambiente político-institucional que pueden comprometer la institucionalización del campo.

Palabras clave: políticas públicas - Brasil, institucionalización, revisión de literatura

Theoretical approaches in the field of public policy in Brazil and abroad: from fact to complexity

Analysis of the trajectory of the field of Public Policy in Brazil and its main challenges, with focus in the subfield of Policy Studies. The paper considers specially the literature that discusses the policy process. After presenting the main theories of public policy, the paper presents the trajectory of the policy studies in Brazil. The article highlights, in contemporary theories, the incorporation of complexity and the presence of non-governmental actors; the shifting of studies from decision-making to other "stages" of the policy process and the recognition of the relevance of institutions, politics, and ideas and values in determining state action. It also shows how, in the recent expansion of literature on public policy in Brazil, despite the tendency towards dispersion and fragmentation, it occurred an incorporation of contemporary theoretical approaches. It highlights, among the challenges, the politicalinstitutional environment as a threat to the institutionalization of the field.

Keywords: public policies - Brazil, institutionalization, literature review 


\section{Introdução}

Já se passaram cinquenta anos da iniciativa pioneira de institucionalização do campo de política pública no Brasil, com a criação do primeiro curso de mestrado em Administração Pública na EBAP-FGV, iniciativa que sofreu descontinuidade sob influência do ambiente político-institucional que caracterizou o regime autoritário. E cerca de trinta anos, da embrionária institucionalização do campo ocorrida no contexto da redemocratização, sob liderança da Ciência Política. Hoje, o campo de política pública no Brasil parece consolidado. Nas últimas décadas, ocorreu uma expressiva expansão da produção acadêmica e da formação com foco em políticas públicas, acompanhada por uma (re) institucionalização do campo como um campo multidisciplinar, processo favorecido por um contexto de valorização da educação superior e da formação na área pública.

O presente artigo apresenta uma análise da trajetória do campo de política pública, considerando a literatura produzida sobre o tema. A institucionalização de um campo científico requer a delimitação de um objeto específico, distinto do abordado por outras disciplinas ou campos científicos ou abordado de maneira singular pelo novo campo. Para que um campo se institucionalize, é preciso ainda que haja articulação entre ideias e suporte material (como instituições de ensino e pesquisa e revistas especializadas) e o controle de recursos estratégicos (BOURDIEU, 1976; Melo, 1999; FARAH, 2016). E, finalmente, é necessária a constituição de uma comunidade discursiva, reunida em torno de uma agenda e de um discurso comuns e de uma identidade compartilhada (OSPINA-BozZI, 1998).

O modo específico, singular, de análise de políticas públicas que distingue esse campo de tradições anteriores de estudos e análises de políticas, consiste no foco no processo. Como sugere Sabatier (1991), embora haja outras vertentes de estudos de políticas públicas, a que se desenvolveu com foco no processo de produção de políticas foi a que propiciou o surgimento, nos anos 1960, nos EUA, de um campo de política pública, dando origem a várias teorias explicativas sobre a formulação, a implementação e sobre os efeitos das políticas, as quais subsidiaram a aplicação de conhecimento no próprio processo ${ }^{12}$

\footnotetext{
${ }^{1}$ Segundo Sabatier (1991), são quatro as principais vertentes da literatura sobre política pública: a) estudos substantivos setoriais; b) estudos de impacto e avaliação; c) estudos do processo de política pública; e d) estudos dos efeitos do design das políticas sobre os resultados. Este artigo tem por referência a terceira vertente, que deu origem à institucionalização do campo.

${ }^{2}$ Dados os limites do presente artigo, não será possível discutir a institucionalização do campo de política pública naquele país, mas é importante assinalar que a criação de cursos de mestrado em Administração Pública-Política Pública exerceu um papel central na institucionalização do campo nos EUA (ALISSON, 2008; FARAH, 2011, 2016).
} 
No Brasil, nos anos 1980, já havia uma produção expressiva sobre políticas, com ênfase em aspectos substantivos de cada política. Mas o campo de política pública só começa a se institucionalizar com a busca da compreensão do processo de produção da política. Nesse campo, a preocupação central é entender (e subsidiar) o processo de política pública. Em torno dessa agenda comum emerge uma comunidade epistêmica (HAAS, 1992), que se constitui por meio do debate e do intercâmbio de ideias, teorias, pesquisas e reflexões sobre práticas, envolvendo pesquisadores de diversos países.

Este artigo apresenta a trajetória do campo por meio da análise da literatura internacional, discutindo, em seguida, a institucionalização do campo no Brasil, destacando temas priorizados pela produção nacional e a presença de abordagens identificadas na literatura internacional.

\section{Teorias de política pública: da ação (racional) do Estado ao reconhecimento da complexidade e da presença de atores não estatais}

Artigo de Pierre Muller ilumina a especificidade do campo de política pública, constituído tardiamente na França a partir dos anos 80 do século passado (MULLER, 2000). A partir da tradição francesa de reflexão sobre o Estado, o autor destaca o foco na ação do Estado como a principal inflexão introduzida pela análise de políticas públicas: "Ce qui caractérise le mieux le renversement opéré par analyse des politiques publiques est le fait qu'elle entend saisir l'État a partir de son action" ${ }^{3}$ (MULLER, 2000,p. 190). O estudo e a análise da política pública teriam, segundo esse autor, permitido "abrir a caixa preta" do Estado, indo além dos estudos de suas determinações, para apreendê-lo a partir de sua ação, procurando entender seu funcionamento.

Skocpol chamara a atenção anteriormente para uma reorientação ocorrida nas Ciências Sociais nos EUA, a partir do final dos anos 1960. A política e as atividades governamentais eram explicadas, até então, a partir de um paradigma sociocêntrico. O Estado era considerado um conceito ultrapassado, sendo um tópico ausente da literatura acadêmica daquele país, privilegiando-se a análise de governos como uma arena onde atores sociais disputavam entre si para influenciar a decisão. Em sua obra "Bringing the State Back In", a autora mostra que, no final dos anos 1960, o Estado passa a ser reconhecido como ator, passando a ocupar um lugar central na produção norte-americana (SKOCPOL, 1985). Essa mudança de paradigma - da explicação da política e dos governos a partir da sociedade

\footnotetext{
3 "O que caracteriza melhor a inflexão operada pela análise de políticas públicas é que ela pretende apreender o Estado a partir de sua ação" (tradução livre da autora).
} 
para o reconhecimento do Estado como ator - foi um dos elementos centrais à institucionalização do campo de política pública nos EUA (HENRY,1975).

Embora as tradições das Ciências Sociais fossem muito distintas nos dois países - nos EUA foi preciso "trazer o Estado de volta"; na França, o Estado já era central como conceito e como objeto de análise -, o exame do Estado por dentro ou ainda do Estado em ação (JOBERT; MULLER, 1987) significou, nos dois casos, uma ruptura de paradigma.

Analisar a ação do Estado implica descrever e explicar a ação estatal e como ela se desenvolve e, ao mesmo tempo, oferecer subsídios para essa ação. Laswell, um dos "pais fundadores" das Policy Sciences, destacava essa dupla face do novo campo - conhecimento sobre o processo da política e no (e para o) processo da política: "The policy sciences may be conceived as knowledge of the policy process and of the relevance of knowledge in the process"4. (LASWELL, 1970, p. 3). Em ambas essas faces, prevaleceu inicialmente uma concepção da política pública como um processo racional, passível de ser desenvolvido de forma científica e neutra.

A ação do Estado era concebida como uma ação racional que tinha por base uma sucessão de passos lógicos que se iniciavam com a definição do problema e a identificação de suas causas, seguindo-se o desenho de alternativas de ação e a escolha de uma alternativa, após a comparação entre elas, com base numa análise de custo-benefício. A noção de ciclo, presente na obra seminal de Laswell, orientava tanto as pesquisas que buscavam explicar o processo como a orientação para a ação, oferecida por policy analysts.

No desenvolvimento do campo, prevaleceu, nessa fase inicial, a ideia de que o problema público e a política existem como fatos, a serem apreendidos pelo analista, a partir da utilização do método científico, conduzindo à hegemonia da abordagem positivista (FISCHER; MILLER; SIDNEY, 2007). Simon foi um dos autores que primeiro destacou os limites da racionalidade no processo de política pública, chamando a atenção para a existência de limitações informacionais e cognitivas (SIMON, 1972). Mas talvez se possa atribuir a Lindblom o primeiro questionamento do paradigma da racionalidade. Esse autor criticou a ideia de ciclo como uma sucessão de passos baseados na identificação inequívoca de um problema público. Na definição do problema, na escolha de uma alternativa e na formulação da política, interferem valores e a política. Além disso, o processo de produção da política não é linear e unidirecional, mas um processo incremental que envolve tentativa e erro (LINDBLOM, 1959), o que também "desmonta" a ideia clássica de planejamento racional, típico da racionalidade instrumental. O processo incremental envolve ainda uma série de

4 "As policy sciences podem ser concebidas como conhecimento do processo de política pública e [como conhecimento] da relevância do conhecimento no processo" (tradução livre da autora). 
pequenas decisões, com a participação de diversos atores (decisores), o que exige interação e negociação, demonstrando o caráter político do processo de produção de políticas (MARQUES, 2013).

A influência da política foi também apontada por autores como Etzioni, Lowi, Barch e Baratz e Lukes (MARQUES, 2013), e o paradigma da racionalidade, questionado por Cohen, March e Olsen (1972). Segundo o modelo de "Garbage Can", proposto por esses autores, a decisão ocorre de forma inversa à sequência problema-solução. Os gestores, diante de limitações das capacidades estatais, escolheriam o problema a ser "resolvido" (MARQUES, 2013). Há nesses questionamentos um embrião do desenvolvimento ulterior do campo, marcado pela presença de teorias alternativas que passaram a disputar espaço com a tradição racional-positivista (ROTH DEUBEL, 2014).

O neoinstitucionalismo, em suas três vertentes, marca uma das inflexões ocorridas a partir dos anos 1980, ao destacar o papel das instituições formais e informais na determinação da conduta dos atores, ora enfatizando o papel das instituições na inibição do autointeresse (escolha racional), ora a relevância de quadros normativos e culturais como referencial para a ação individual (sociológico), ora ainda destacando o papel de trajetórias prévias nas escolhas de alternativas de política e a relevância das instituições para a regulação de conflitos e de assimetrias de poder (histórico) (THÉRET, 2003; TAYLOR; HALL, 2003). A contribuição do neoinstitucionalismo histórico se destaca pela ênfase dada por essa vertente ao estudo do Estado e das políticas (MARQUES, 2013).

A abordagem cognitiva assinala outra inflexão paradigmática, ocorrida também nos anos 1980. Essa perspectiva destaca o papel das ideias, das crenças e do conhecimento. A escolha de uma alternativa seria influenciada por valores e ideias e não algo neutro derivado de uma racionalidade instrumental.

Sabatier e Schlager (2000) identificam três correntes no interior dessa abordagem. A minimalista, representada por autores como King, Goldenstein e Keohane, veria as ideias como uma forma de legitimar a ação, prevalecendo na análise, em última instância, fatores não cognitivos. A variante equilibrada, que inclui autores como Kingdon, Baumgarten e Jones, Ingram e Schneider e o próprio Sabatier e seus colegas, busca um equilíbrio entre fatores cognitivos e não cognitivos, isto é, entre ideias, instituições e fatores socioeconômicos. Finalmente, Sabatier e Schlager (2000) identificam uma terceira variante, maximalista, representada por autores como Rein e Schon, Roe e por Muller, Surel e Palier, na qual, ao se insistir na importância das ideias, excluem-se fatores não cognitivos ${ }^{5}$.

${ }^{5}$ Palier e Surel (2005) defendem a integração na análise de três "Is": ideias, instituições e interesses, o que refuta a leitura de Sabatier e Schlager (2000) de exclusão da análise de fatores não cognitivos. 
Na corrente maximalista, destaca-se a noção de "quadro de ação pública" (frame), de Rein e Schon (1996), que consiste numa maneira de selecionar, organizar, interpretar e atribuir sentido a uma realidade complexa, fornecendo uma referência para a análise, para a persuasão e para a ação. Diante de problemas complexos, tende a haver controvérsia entre diferentes frames, entre diferentes enquadramentos do problema, elaborados por meio de diferentes narrativas. O trabalho do analista consiste em "desvendar" os diferentes enquadramentos subjacentes aos discursos dos atores e contribuir para o reenquadramento de problemas públicos, possibilitando que os diversos atores envolvidos se apropriem da reflexão sobre os frames em disputa (REIN; SCHON, 1996). Rein destaca aspectos do policy process que evidenciam os limites da racionalidade instrumental na análise de problemas complexos, como os conflitos de valores e a ambiguidade dos fins (REIN, 2008).

A escola francesa, por sua vez, problematiza um dos elementos centrais à constituição do campo, relativa aos objetivos da política. Sem rejeitar a ideia de que a política pública procura resolver problemas públicos, autores filiados a essa corrente afirmam que a política pública constitui um quadro de interpretação do mundo que orienta a ação do Estado e dos atores sociais (MULLER, 2000). As políticas, assim, ao construírem quadros de interpretação do mundo, fornecem referenciais à ação pública, condicionando a escolha de alternativas e orientando a definição do problema público e a escolha de políticas (MULLER, 2010).

Peter Hall (1993) trabalha com a noção de quadro de interpretação do mundo, ou matriz cognitiva, na perspectiva do Policy Learning, aplicando a noção de paradigma, de Kuhn, ao conjunto de ideias, crenças e conhecimento que influencia a formulação de políticas. A importância do conhecimento para o processo de produção de políticas é destacada, por sua vez, por autores como Sabatier (1988) e Haas (1992).

Roth Deubel (2014) diferencia, no interior da vertente que Sabatier e Schlager classificam como maximalista, a corrente interpretativista, que inclui a análise de narrativa de Roe e a análise deliberativa de Fischer e Forester, Hajer e Wagenaar. Segundo o interpretativismo, a abordagem tradicional, baseada na investigação científica de dados objetivos e na comprovação empírica de hipóteses, teria fracassado na descoberta de evidências cientificamente comprovadas úteis à tomada de decisão e se afastado da missão democratizadora do campo de políticas públicas. O interpretativismo adota a epistemologia construtivista, a partir de uma perspectiva crítica, atribuindo importância ao contexto, aos saberes locais e aos argumentos dos atores sociais, e conduzindo a uma revisão 
da postura do analista, que deixa de ser o detentor de uma autoridade conferida pelo conhecimento científico (ROTH DEUBEL, 2014).

Roe propõe a análise de narrativas para o estudo de controvérsias no processo de política pública e considera essa abordagem - típica do construtivismo particularmente pertinente em situações de grande complexidade, incerteza e polarização extrema entre atores. A criação de um meta-relato, derivado do estudo de narrativas que participam da controvérsia, possibilita superar limites de ferramentas tradicionais da análise de políticas, por meio do reconhecimento da importância de fatores subjetivos, cognitivos, narrativos e retóricos no processo de decisão, abrindo espaço para a persuasão (RoE, 1989; Roth DEUBEL, 2014).

Autores como Fisher, Forester, Hajer e Radin destacam a centralidade da argumentação e da deliberação, propondo uma virada argumentativa (argumentative turn) no campo da política pública (FISHER; FORESTER, 1996; HAJER, 1996; RADIN, 2000; FISCHER; MILler; SIDNEY, 2007). Essa perspectiva aprofunda a crítica à abordagem racional-empiricista, adotando uma postura pós-positivista (FISCHER, 1998). O questionamento das abordagens clássicas critica o afastamento da pesquisa e da produção em política pública de um dos elementos centrais da proposta formulada por Laswell - a orientação por valores democráticos. Assim, questionando simultaneamente a capacidade explicativa das teorias racionalistas e o descolamento tecnocrático dos analistas em relação aos problemas públicos e aos atores afetados pelos problemas e pelas políticas, a perspectiva argumentativa destaca a importância da deliberação baseada na argumentação. As "evidências" não são suficientes para conduzir a uma solução, no caso de problemas complexos, que suscitam distintas interpretações (FISCHER; FORESTER, 1996; FISCHER, 1998; HAJER, 1996). Na vertente maximalista, o compromisso do estudioso de política pública com a prática é enfatizado, resgatando uma das missões do campo, destacada por Laswell e que, segundo essa perspectiva, foi se perdendo na vertente mainstream de corte positivista (ROTH DEUBEL, 2014).

Outro tipo de inflexão nas teorias sobre o processo de política pública envolveu o questionamento da centralidade da formulação. O paradigma da racionalidade e a noção de ciclo atribuíam à decisão a capacidade de definir todo o processo, restringindo-se as teorias a explicar esse "momento-chave", e as análises (policy analysis), a orientar e subsidiar essa etapa do ciclo. Havia, assim, um modelo topdown que entendia que a implementação era inteiramente definida no momento da decisão. A partir dos anos 1970, diversos autores questionaram esse modelo de implementação e a noção de ciclo como uma sucessão lógica e temporal de etapas. Pressman e Wildavsky (1984) procuraram demonstrar que a implementação transforma a política e que, portanto, a redefine e a re(formula). Ao destacarem 
problemas de implementação envolvendo diferentes níveis da federação, chamaram a atenção também para a importância das relações intergovernamentais e da coordenação interfederativa. Posteriormente, Lipsky (2010, primeira edição em 1980) chamaria a atenção para a discricionariedade de burocratas de nível de rua, mostrando como esses também tomam decisões, sendo essa discricionariedade um elemento central da adaptação de políticas a diferentes contextos.

O questionamento da centralidade do processo de formulação ocorreu ainda com o desenvolvimento de estudos sobre formação da agenda, que criticam a visão do problema como um fato a ser apreendido pelo analista, implícita no paradigma da racionalidade. Estudos sobre agenda mostram que a própria definição do problema é influenciada por valores e ideias, sendo também objeto de disputa política, e que a entrada de um tema na agenda envolve processos não racionais, como afirma a teoria de múltiplos fluxos de Kingdon (1995). Baumgartner, Jones e Mortensen (1999) contribuem adicionalmente ao propor uma teoria para análise de políticas públicas em situação de mudança, atribuindo também papel relevante às ideias por meio do conceito de policy image.

Foram destacadas até aqui inflexões nas abordagens teóricas que correspondem à incorporação pela análise de elementos ausentes ou negligenciados pela abordagem racional-instrumental que marcou a institucionalização do campo nos anos 1960. Tais inflexões ocorreram diante do reconhecimento da insuficiência da abordagem clássica. Mas a insuficiência dos modelos explicativos iniciais foi potencializada diante de transformações no processo de política pública, especialmente a partir dos anos 1980 (RADIN, 2000).

Dentre essas transformações, destacam-se mudanças no objeto de análise, no lócus de produção da política e nos atores envolvidos no processo. Em relação ao objeto de análise, o reconhecimento da complexidade dos problemas públicos evidenciou os limites da abordagem tradicional. Rittel e Weber argumentaram, ainda nos anos 1970, que os problemas públicos constituem wicked problems que não se prestam ao tratamento proposto pela abordagem científica positivista: não são passíveis de uma definição única e inequívoca; não é possível levantar e processar todas as informações e dados relevantes sobre cada problema; e não há uma solução definitiva e objetiva identificável (RITTEL; WEBBER, 1973). Para esses autores, os wicked problems são caracterizados pela combinação de três elementos: complexidade, incerteza e divergência em relação a valores (RITTEL; WEBBER, 1973). A busca de maior eficiência na 
geração de resultados pela New Public Management também enfrentaria limites, segundo essa perspectiva, diante de problemas públicos complexos, marcados por expectativas divergentes (HEAD, 2008).

Diante de problemas complexos, caracterizados pela incerteza e por visões distintas derivadas de valores em disputa, não há saída fácil. É preciso reconhecer a natureza "wicked" (perversa) dos problemas e buscar alternativas que levem em consideração a especificidade de cada caso, de cada contexto e os atores e valores envolvidos. Mas, além disso, é preciso contar com a participação de diversos atores - governamentais e não governamentais - para lidar com esse tipo de problema (HEAD, 2008).

A partir dos anos 1980, houve uma redefinição do lócus do processo de produção das políticas, que deixa de ser exclusivamente o Estado e as agências estatais, passando a incluir também organizações não governamentais, o setor privado, organizações comunitárias e movimentos sociais (RADIN, 2000). A análise da política pública passa a ter como objeto, portanto, não apenas a ação estatal, mas também a ação de atores não governamentais que participam do processo de identificação e definição do problema público, de sua inclusão na agenda, da formulação da política e de sua implementação e avaliação (FREDERICKSON, 1999; SUBIRATS et al., 2008). As políticas tendem a envolver, por outro lado, diversas agências e setores estatais em sua concepção e em sua implementação, assim como diversos níveis de governo.

As alterações relativas aos atores e instituições e aos níveis de governo envolvidos nas políticas trouxeram desafios teóricos e práticos para o campo, e conduziram ao desenvolvimento de teorias e conceitos que procuram apreender as dinâmicas do processo de política pública, bem mais complexas do que o arcabouço racional-positivista podia abarcar. Alguns conceitos têm por referência essa multiplicidade de lócus, de atores e de níveis e agências governamentais. Conceitos como os de issue network (HECLO, 1995 „, artigo original de 1978), redes de políticas públicas (policy networks) (RODHES, 2008), comunidade de política (policy community) ( JORDAN, 1990) e comunidade epistêmica (HAAS, 1992) destacam relações entre atores e entre organizações implicadas com políticas específicas, destacando a inserção diversificada dos atores - em organizações governamentais e não governamentais, em diferentes agências e setores governamentais, em diversos níveis de governo e em instituições supranacionais. O conceito de governança também procura apreender essa nova dinâmica de que participam múltiplos atores e diversas instâncias governamentais (RHODES, 2008; Peters; PierRe, 2002). 
Mais recentemente, a Teoria Ator-Rede, desenvolvida originalmente no campo de Ciência, Tecnologia e Sociedade por Latour, Callon e Moll, foi trazida para o campo de estudos de políticas públicas. Artigo de Grau-Solés, Íñiguez-Rueda y Subirats (2011) enfatiza a complexidade da realidade e dos problemas públicos e propõe a figura topológica do "objeto múltiplo" em substituição à noção de rede, como mais adequada para apreender uma realidade que "é" não apenas complexa, mas múltipla. Os autores propõem ainda a noção de integralidade das políticas públicas, que dê conta da complexidade e da multiplicidade.

O artigo de Grau-Solés, Íñiguez-Rueda e Subirats (2011) adota o conceito de ação pública utilizado por alguns autores no Brasil, para se referir ao espaço, por vezes colaborativo, por vezes conflituoso, de intersecção entre a política pública e os movimentos sociais, entre a ação governamental e a ação de atores da sociedade civil (SPINK, 2007), tendo por base definição de Drèze e Sen (1997). A integralidade tem sido também enfatizada pela literatura latino-americana, sobretudo na perspectiva da intersetorialidade (CUNILL-GRAU, 2014; COSTA; BRoNZO, 2012).

A transversalidade, por sua vez, foi incorporada pela literatura de política pública a partir da adoção da estratégia de gendermainstreaming pela União Europeia, no final dos anos 1990 (PAPA, 2012). O primeiro artigo a discutir o tema foi publicado em 2000, abordando a proposta de incorporação da perspectiva de gênero por todas as políticas públicas nos países da União Europeia, destacando o papel do movimento feminista na adoção dessa estratégia (POLLACK; HAFNER-BURTON, 2000). A temática da transversalidade envolve duas dimensões importantes, contempladas pela literatura recente sobre política pública: a relativa ao reconhecimento da diferença entre grupos beneficiários de políticas - mantido o princípio de igualdade de direitos dos cidadãos e cidadãs -; e a que diz respeito à relevância de movimentos sociais para a inclusão de temas na agenda governamental. O Quadro 1 sintetiza as principais inflexões nas abordagens teóricas desenvolvidas no campo de políticas públicas a partir da literatura internacional. 


\section{Quadro 1 - Teorias de política pública ${ }^{6}$}

\begin{tabular}{|c|c|}
\hline Abordagens teóricas & Aspectos centrais das teorias \\
\hline Racional-positivista & 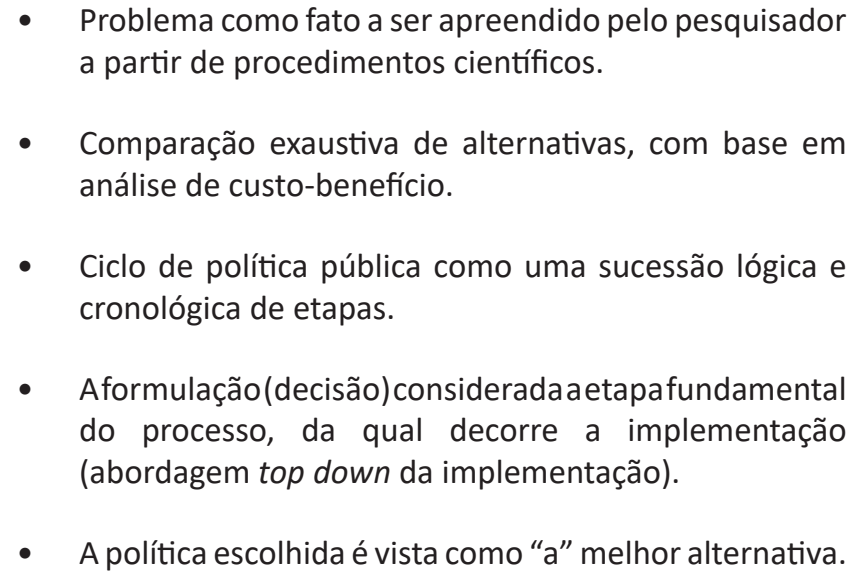 \\
\hline Racionalidade limitada & $\begin{array}{l}\text { - Existência de limitações informacionais e cognitivas na } \\
\text { definição do problema e no estudo de alternativas. } \\
\text { - A política escolhida é a melhor diante das informações } \\
\text { disponíveis e da capacidade de processamento de } \\
\text { informações no estudo de alternativas. }\end{array}$ \\
\hline $\begin{array}{l}\text { Incrementalismo } \\
\text { e Teoria do Ótimo } \\
\text { Normativo }\end{array}$ & $\begin{array}{l}\text { - Influência de fatores políticos e de valores no estudo } \\
\text { de alternativas. } \\
\text { - Limitações de tempo e de recurso dificultam o estudo } \\
\text { exaustivo de alternativas. } \\
\text { - As comparações se dão como um processo sucessivo } \\
\text { e limitado. } \\
\text { - A alternativa é escolhida com base em um processo de } \\
\text { - } \quad \text { O processativa e erro. } \\
\text { - A alternativa é a possível (inclusive considerando } \\
\text { fatores políticos) e não "a melhor" e ótima. } \\
\text { - Influência de fatores extrarracionais. }\end{array}$ \\
\hline
\end{tabular}

${ }^{6} \mathrm{O}$ Quadro 1 procura destacar inflexões nas abordagens teóricas mencionadas no texto, de forma sintética e panorâmica. Não pretende ser exaustivo, não nomeando todas as teorias mencionadas no corpo do artigo. 


\begin{tabular}{|c|c|}
\hline Garbage Can & $\begin{array}{l}\text { - Inversão da sequência problema-solução. } \\
\text { - Diante de limitações das capacidades estatais, os } \\
\text { gestores escolhem o problema a ser "resolvido". } \\
\text { - Soluções desenvolvidas anteriormente são buscadas } \\
\text { numa "lata de lixo" para solucionar o problema } \\
\text { escolhido. }\end{array}$ \\
\hline $\begin{array}{l}\text { Neo-institucionalismo } \\
\text { - Escolha racional } \\
\text { - Sociológico } \\
\text { - Histórico }\end{array}$ & $\begin{array}{l}\text { - Os atores que tomam a decisão (formuladores) } \\
\text { - selecionando a alternativa a ser adotada - são } \\
\text { condicionados por instituições formais e informais } \\
\text { (regras, incentivos ...). }\end{array}$ \\
\hline $\begin{array}{l}\text { Abordagem cognitiva e } \\
\text { ênfase a ideias } \\
\text { - Minimalista } \\
\text { - Moderada } \\
\text { - Maximalista } \\
\text { (interpretativista } \\
\text { e argumentativa) }\end{array}$ & $\begin{array}{l}\text { - Destaca o papel de ideias e valores na definição do } \\
\text { problema e na escolha de alternativas. } \\
\text { - Quadros interpretativos, referenciais ou frames } \\
\text { estruturam a forma com que o ator percebe o mundo } \\
\text { (e o problema público), servindo de referência para a } \\
\text { análise e para a ação. } \\
\text { - A política pública não é vista apenas como resposta a } \\
\text { um problema público. } \\
\text { - A própria política pública participa da construção de } \\
\text { um quadro interpretativo que orienta as ações dos que } \\
\text { tomam decisão. } \\
\text { Questiona a visão de ciclo e a abordagem “tecnocrática" } \\
\text { do processo de política pública (racional-positivista). } \\
\text { - Destaca a existência de controvérsias a respeito do } \\
\text { "problema público". } \\
\text { Enfatiza a complexidade do problema público. } \\
\text { Defesa da proximidade entre análise e prática } \\
\text { e do compromisso e à deliberação baseada na } \\
\text { argumentação. }\end{array}$ \\
\hline
\end{tabular}




\begin{tabular}{|c|c|}
\hline $\begin{array}{l}\text { Teorias sobre formação } \\
\text { da agenda }\end{array}$ & $\begin{array}{l}\text { - Questionamento da concepção do problema público } \\
\text { como um fato a ser apreendido pelo analista. } \\
\text { - A definição do problema é influenciada por ideias e } \\
\text { valores. } \\
\text { - A própria definição do problema é objeto de disputa } \\
\text { política. }\end{array}$ \\
\hline $\begin{array}{l}\text { Diversas teorias } \\
\text { contemporâneas }\end{array}$ & $\begin{array}{l}\text { - Reconhecimento da ampliação do lócus da produção } \\
\text { de políticas - para além do Estado/governo. } \\
\text { - Análise passa a incluir diversos atores que participam } \\
\text { da formação da agenda, da formulação e da } \\
\text { implementação das políticas (atores estatais e não } \\
\text { estatais). } \\
\text { - Análise considera a participação de diversos níveis de } \\
\text { governo nas políticas públicas. } \\
\text { - Mobilização de conceitos e abordagens que } \\
\text { incorporam essas mudanças: rede, comunidade de } \\
\text { política, comunidade epistêmica, advocacy coalition, } \\
\text { entre outros. } \\
\text { - Análise do processo de política pública em situações } \\
\text { de mudança. } \\
\text { Desenvolvimento do conceito de governança e de } \\
\text { governança multinível. } \\
\text { Estudos sobre coordenação federativa e relações } \\
\text { intergovernamentais. }\end{array}$ \\
\hline
\end{tabular}

Fonte: elaboração própria.

\section{Estudos de políticas públicas no Brasil: descontinuidade, fragmentação e incorporação da agenda democrática}

No Brasil, não foi preciso trazer o Estado de volta (Melo, 1999). O Estado constituiu um dos eixos do pensamento social e político brasileiro desde o início do século 20. Mas, também aqui, os estudos de políticas representaram uma inflexão importante na análise do Estado. À semelhança do que se verificou na França, com o desenvolvimento de estudos de políticas públicas, houve um deslocamento de uma análise do Estado como um bloco (MELO, 1999) para estudos do Estado "por dentro", da ação do Estado ou do Estado em ação. Essa inflexão foi marcada, de um lado, pela presença de temas e problemas que se destacavam na agenda societária 
e governamental do país e, de outro, pela influência do desenvolvimento do campo nos EUA (FARAH, 2011, 2016).

A incorporação da abordagem da política pública pelos estudos sobre o Estado se deu por duas vertentes, que ora se interpenetraram, ora se afastaram. De um lado, pela vertente dos estudos de políticas públicas (policy studies), em que se buscava explicar o processo de produção das políticas. De outro, pela vertente da policy analysis, cujo foco era fornecer subsídios para políticas públicas (VAITSMAN; RIBEIRO; LOBATO, 2013). Em ambos os casos, havia um leitmotiv comum - contribuir para a busca de respostas a problemas públicos destacados pela agenda societária e governamental.

Número especial da Revista de Administração Pública, de 1976, reúne trabalhos apresentados no "Seminário Internacional sobre Análise de Política Pública", realizado em 1975, na Escola Brasileira de Administração Pública (Ebap) da Fundação Getúlio Vargas, nos quais sobressai a reflexão sobre as abordagens analíticas então em debate no campo, nos EUA. Na apresentação da revista, fica claro o foco na análise do processo de decisão:

A análise de políticas públicas [...] constitui hoje a fronteira mais avançada no estudo de administração pública e governo. Seu objetivo é a análise de decisões governamentais [...], do ponto de vista dos fatores que as influenciam, das alternativas consideradas e selecionadas, do processo de tomada de decisão, assim como do impacto social e econômico das políticas adotadas (PALAVRAS..., 1976, p. 3, grifo nosso).

Era clara a conexão de autores brasileiros com a produção norte-americana: a centralidade no processo de decisão, como visto, marcou as primeiras teorias sobre política pública nos EUA. Destaca-se, por outro lado, a referência a autores como Lindblom e Dror, que já então questionavam a perspectiva da racionalidade (LIMA JÚNIOR; SANTOS, 1976; REIS, 1976). Extremamente interessante é a revisão da literatura sobre política pública feita por Otavio Lima Júnior e Wanderley Guilherme dos Santos, em que distinguem duas vertentes analíticas, antecipando Skopcol (1997, 1ำ edição 1985): uma primeira, externalista, consideraria as políticas públicas como dependentes da estrutura social e, portanto, de fatores externos ao Estado; uma segunda, internalista, veria as políticas públicas como sendo determinadas por características do próprio Estado e se dedicaria a estudar "os processos decisórios dentro da estrutura governamental” (LIMA JÚNIOR; SANTOS, 1976, p. 243). Os autores propõem uma combinação, no estudo de políticas públicas, de elementos das duas vertentes. 
Fabio W. Reis registra, por sua vez, a incorporação pela Ciência Política, por meio de estudos de políticas públicas, de "técnicas aparentemente tão 'difíceis' como análise de sistemas, análise de custo e benefício, orçamento-programa" (REIS, 1976, p. 51), considerando esse esforço parte do propósito de obtenção do status científico por parte da disciplina. O autor questiona, no entanto, a negação da política - "a despolitização do trabalho dos estudiosos" (REIS, 1976, p. 58).

A iniciativa de institucionalização do campo de política pública no Brasil nesse momento teve como um de seus eixos a formação em Administração Pública. $O$ primeiro curso de mestrado em Administração Pública do país, o da Ebap, entendia a formação em Administração Pública como formação de analistas de políticas públicas (FARAH, 2016). Mas esse processo foi interrompido durante o regime militar, deixando de haver apoio à formação, à pesquisa e à produção acadêmica nessa área (FISCHER, 1984; StATION-WELNA, 2002; FARAH, 2016). No entanto, isso não significa que não tenha ocorrido influência no Brasil do campo de política pública, tal qual este se configurou nos EUA, mesmo no período autoritário. Essa se exerceu - na vertente da Policy Analysis - sobretudo por meio de estudos desenvolvidos fora da academia, por instituições estatais, com base nas metodologias de corte racionalpositivista que então ainda eram dominantes na policy analysis norte-americana7 (Velloso, 2004; VAitsman; Ribeiro; Lobato, 2013; FARAH, 2016).

Os estudos de políticas públicas (policy studies), por sua vez, desenvolveram-se, a partir dos anos 1970 e 1980 (MElo, 1999; SouZA, 2006; MARQUES, 2013), por meio de pesquisas sistemáticas sobre a ação do Estado, de base empírica, destacando-se o Núcleo de Políticas Públicas (NEPP) da Unicamp, o luperj, assim como o Grupo de Trabalho de Políticas Públicas da Associação Nacional de Pesquisa e Pós-Graduação em Ciências Sociais (Anpocs). A produção foi marcada, já nesse momento, por diferentes orientações. De um lado, por um viés sociológico, tendo como centro o estudo de políticas sociais e do sistema de proteção social brasileiro, em que se destaca a atuação do NEPP (DRAIBE, 1983; NEPP/Unicamp, 1985); de outro, por uma orientação mais próxima à tradição norte-americana, ligada ao luperj, a qual tinha como foco principal o processo decisório, analisando a intermediação de interesses na formação de políticas (MELo, 1999). Em ambos os casos, havia um distanciamento da perspectiva positivista de base racional que marcou a primeira "onda" de teorias sobre política pública quando da institucionalização do campo nos EUA nos anos 1960.

\footnotetext{
${ }^{7}$ Reis Velloso, presidente do Ipea entre 1964 e 1968, destaca o objetivo de realização de pesquisas orientadas para políticas públicas pela instituição, criada em 1964: "Pretendíamos que o Ipea fizesse pesquisa econômica aplicada, ou seja, policy-oriented, e que ajudasse o governo a formular o planejamento, numa visão estratégica de médio e longo prazos" (Velloso, 2004, grifo nosso).
} 
Os anos 1970 e os 1980 também foram marcados por estudos específicos sobre setores de políticas sociais, para os quais contribuíram diversas disciplinas (VAlladares, 1981; Melo, 1999; FARAH, 2016 b). Essa vertente evidencia a importância na agenda de pesquisa, nesse momento, de temas sociais, ao lado dos ligadas ao desenvolvimento. Se, de um lado, esses estudos setoriais contribuíram para a problematização da questão social no país e para a reflexão crítica sobre as políticas, por outro, houve uma fragmentação da produção, dificultando a institucionalização de um campo em torno de uma identidade comum (OSPINABozzı, 1998; Melo, 1999). Essa literatura tinha como foco questões substantivas referentes a cada setor de política social, não abordando o processo de produção das políticas, o que, como visto, foi o que possibilitou a emergência do campo de política pública.

A produção liderada pela Ciência Política, por sua vez, possibilitou uma institucionalização do campo - ainda que embrionária - ao ter como eixo estudos que transcendem setores e procuram analisar elementos comuns ao processo de produção das políticas ${ }^{8}$, com ênfase, inicialmente, a características institucionais. Essa nova produção nacional sobre política pública tinha conexões com a produção internacional, incorporando os novos referenciais teóricos críticos às abordagens iniciais de corte positivista.

Esse processo ocorreu em um contexto marcado pela agenda da democratização, orientada para a extensão do acesso a serviços públicos e para a participação de novos atores no processo decisório. Foram incorporados, assim, à agenda de pesquisa temas centrais da agenda societária, como participação, descentralização e redução da desigualdade. Essa agenda interna era convergente com mudanças em curso na literatura internacional que procuravam incorporar à análise a presença de novos atores no processo de formulação e implementação das políticas (FREDERICKSON, 1999).

Do ponto de vista temático, a literatura passou a incluir uma outra face da agenda democratizante: a relativa à incorporação à cidadania e às políticas públicas de grupos até então excluídos ou atendidos de forma periférica, como mulheres, negros, indígenas, grupos LGBTT e deficientes. A inclusão desses temas pela agenda governamental foi influenciada por movimentos sociais e por organizações não governamentais e entidades de advocacy. Esses atores também ajudaram a colocar na agenda novos problemas públicos, como a questão ambiental, o tema da violência e da segurança pública e o da mobilidade urbana, progressivamente incorporados pela literatura de política pública. A presença de atores da sociedade civil por meio de novos arranjos institucionais, como conselhos e conferências,

${ }^{8}$ Retomava-se, assim, iniciativa dos anos 1970, mencionada anteriormente, liderada pela Ebap. 
por sua vez, tornou-se um dos temas destacados pela literatura (DAGNINO, 2002; Petinelli, 2011).

Adicionalmente, passaram a integrar a agenda governamental, sob impacto da crise fiscal e da agenda de reforma do Estado, temas como eficiência, efetividade e controle social, incorporados também pela agenda de pesquisa do novo campo em processo de institucionalização. Diante do papel atribuído aos municípios a partir da Constituição de 88, ganharam ainda importância na agenda de pesquisa as políticas locais e a gestão local de políticas.

O processo de produção de política pública tornara-se mais complexo, colocando novos desafios para a análise. Era preciso apreender a presença de novas instituições e atores, assim como analisar os desafios de coordenação de diferentes níveis de governo, de organizações estatais distintas e de organizações governamentais e não governamentais. Também entraram na agenda desafios relativos ao controle das políticas e à gestão, potencializados com a multiplicidade de atores envolvidos.

Assim, quando, nos anos 2000, ocorreu uma expansão da produção sobre políticas públicas, não apenas as temáticas se diversificaram, mas também novas abordagens teóricas foram mobilizadas. O instrumental analítico baseado na racionalidade era insuficiente para apreender o processo de produção de política pública, havendo também o desafio de deslocamento da análise do processo decisório para outras "etapas" do processo. E o desafio de incorporação ou desenvolvimento de referenciais teóricos que fossem capazes de apreender os novos problemas públicos e a complexidade dos mesmos.

\section{Expansão da produção sobre política pública e (re)institucionalização: desafios de um campo multidisciplinar}

A partir dos anos 2000, especialmente a partir de meados da década, houve um boom de estudos sobre políticas públicas no país, concomitante à expansão da formação na área, sob estímulo de políticas de incentivo à pesquisa e à educação superior, de estímulo à formação em Administração Pública, Política Pública e áreas correlatas e diante do aumento de oportunidades para profissionais com formação em Política Pública (FARIA, 2012; FAdul et al., 2014; FARAH, 2016b). Segundo Faria (2012), levantamento feito no Banco da Capes de teses e dissertações revelou que, entre 1987 e 1990, apenas 63 trabalhos de todas as áreas do conhecimento abordavam o tema política pública, enquanto que, entre 2006 e 2010, o total de

\footnotetext{
${ }^{9} \mathrm{O}$ processo de institucionalização do campo nos EUA, cuja análise ultrapassa o escopo deste artigo, também se apoiou na expansão da formação em administração pública e política pública (FARAH, 2011, 2016).
} 
artigos sobre o tema chegou a 7675. O incremento mais expressivo se deu a partir de 2006 (63,25\% entre 2006 e 2010).

De 291 periódicos nacionais que constavam da base Scielo em 2012, 155 continham pelo menos um artigo cujo resumo apresentava a expressão "política pública". No entanto, apenas 38 periódicos haviam publicado 10 ou mais artigos até esse ano, o que evidencia uma grande dispersão da produção. Mesmo no caso dos periódicos com maior concentração de artigos, é grande a dispersão: 12 são da área de saúde, sete da educação, seis de Ciências Sociais (incluindo Ciência Política e Sociologia), cinco da área multidisciplinar-interdisciplinar, quatro de Psicologia, dois de Administração e Administração Pública, um de Serviço Social e um de Ciência da Informação ${ }^{10}$. Essa tendência à dispersão é confirmada por estudo de TROTTMANN et al. (2017), segundo o qual 2925 autores publicaram artigos sobre políticas públicas em periódicos ou em anais de congressos entre 2000 e 2011, nas áreas de Administração Pública, Ciência Política e Sociologia. No entanto, apenas 1,5\% dos(as) autores(as) publicaram regularmente sobre o tema, estimando-se que 9,9\% tendem a continuar publicando estudos sobre políticas públicas, somando cerca de $11 \%$ de autores do campo. 74,9\% publicaram apenas um artigo (one timers) ${ }^{11}$.

A expansão não alterou tampouco outras características do campo, apontadas pela literatura, em especial a baixa densidade analítica e a predominância de estudos de caso setoriais (Melo, 1999; Arretche, 2003; SouzA, 2003; PACHeCo, 2003), como sugerem estudos recentes (FADUL et al., 2014; FARAH et al., 2016). Mas uma parte da produção nacional vem contribuindo para o reforço de um núcleo temático e para discussões transversais a diversos setores, incorporando abordagens teóricas contemporâneas relativas ao processo de política pública. O neoinstitucionalismo, sobretudo pela vertente do neoinstitucionalismo histórico, está presente em um número considerável de trabalhos (MARQUES, 2013), contemplando temas como descentralização e recentralização, capacidade estatal, federalismo e relações intergovernamentais (ARRETCHE, 2012; ABRUCIO, 2005; BICHIR, 2016; TROJBICZ, 2017). O neoinstitucionalismo também serve de arcabouço teórico para análises de novos arranjos institucionais, em especial das novas instâncias de participação, como conselhos gestores de políticas públicas, orçamento participativo e conferências (WAMPler; AVritzer, 2004; CORTES, 2007), iluminando a discussão de uma das temáticas nucleares do período pós-democratização - a relativa à incorporação de novos atores pelo processo de política pública.

\footnotetext{
${ }^{10}$ Agradeço a Ricardo Beltrão pelo apoio no levantamento da produção sobre política pública em periódicos da base Scielo.

${ }^{11}$ Trata-se predominantemente de artigos gerados por teses e dissertações.
} 
A abordagem cognitiva passou a ser mobilizada por autores brasileiros a partir do início dos anos 2000 (FARIA, 2003), acompanhada por um deslocamento dos estudos do processo decisório para o processo de formação da agenda (BUENO, 2001; CAPELLA, 2008; Simielli, 2013; SouzA; SeCCHI, 2014; Brasil; CAPELLA; SoAReS; BRASIL, 2014). Segundo a classificação proposta por Sabatier e Schlatger (2000), predomina na literatura brasileira a vertente equilibrada da abordagem cognitiva, a qual tem por referência, entre outras, a obra do próprio Sabatier. Segundo levantamento realizado por Lukic e Tomazini (2014), até 2014, 26 publicações se baseavam, na América Latina, no conceito de coalizão de defesa proposto por Sabatier, a maior parte de autores brasileiros. O mesmo levantamento identificou 16 publicações baseadas na noção de referencial de Jobert e Muller (1987); oito, na noção de paradigma de Hall (1993); e cinco, na combinação de diferentes referenciais. Além dos trabalhos identificados por essas autoras, há também artigos que se apoiam na vertente interpretativista, que enfatiza a importância do discurso e da argumentação (FUKS, 2000; CASTRO, 2013; SOUZA; FARAH, 2017).

Também tem crescido o número de estudos da implementação, até recentemente pouco estudada no Brasil, sendo $88 \%$ dos artigos posteriores a 2000 (FARIA, 2012a). Coletânea organizada por Faria (2012b) reuniu estudos pioneiros nessa área, articulando a análise da implementação a temas como discricionariedade da burocracia, intersetorialidade, redes, cooperação e coordenação.

A literatura nacional recente incorporou abordagens que procuram apreender a complexidade do processo de produção de políticas, caracterizado pela participação de uma multiplicidade de atores governamentais e não governamentais, pela existência de situações de ambiguidade quanto à própria posição dos atores (CORTES, 2013) e por controvérsias relativas ao problema público e às alternativas de política. $\mathrm{Na}$ presente década, alguns trabalhos fazem referência a wicked problems e à necessidade de estratégias capazes de lidar com a complexidade e com a presença de controvérsias, como a intersetorialidade e a transversalidade (REINACH, 2013; VEIGA; BRonzo, 2014). A presença de múltiplos atores também é apreendida por meio da mobilização de conceitos como rede de política pública (MARQUES, 1999, 2012; LOTTA; PÁvEZ, 2010); comunidade de política (CORTES, 2007), comunidade epistêmica (COSTA, 2014; FARAH, 2016) e coalizão de defesa (BUENO, 2001; SIMIELLI, 2013; SOUZA; SECCHI, 2014). Alguns trabalhos incorporam a abordagem ator-rede no estudo da formulação da política (ANDRADE, 2006), da implementação (PIRES, 2016) e em estudos sobre programas governamentais nascidos de uma ação pública não governamental (PEREIRA, 2016). 


\section{O perfil atual do campo no Brasil}

A trajetória do campo de política pública no Brasil mostra que se, de um lado, a produção de estudos sobre políticas contribuiu para a institucionalização do campo no país, de outro, essa produção foi, desde o início, afetada pelas condições em que se deu essa institucionalização. Assim, a iniciativa pioneira de institucionalização, nos anos 1960, que incluiu a formação em política pública e foi acompanhada pelos primeiros estudos sobre políticas, foi afetada pela inexistência de apoio a essa área no período autoritário. A produção acadêmica sobre política pública só passou a ser expressiva com a redemocratização, nos anos 1980, dando início à (re) institucionalização do campo centrada em estudos de políticas públicas.

A evolução do campo a partir de então foi marcada pela tendência de fragmentação, com várias disciplinas desenvolvendo estudos sobre políticas, com pouca comunicação entre si. Essa produção se caracterizou ainda pelo predomínio de estudos setoriais de baixa densidade analítica. Mas a vertente que se desenvolveu em torno de estudos sobre o processo de produção das políticas e seus efeitos possibilitou a emergência de um discurso e de uma identidade comuns, condições da institucionalização de um campo científico. Do ponto de vista das abordagens teóricas mobilizadas, o paradigma positivista centrado na racionalidade instrumental que caracterizara os primeiros estudos sobre o processo de decisão na literatura internacional não chegou a impregnar os estudos de políticas no Brasil, embora tenha exercido influência em análises para políticas desenvolvidas por agências governamentais ou realizadas sob demanda do governo, desde os anos 1970. Nos estudos acadêmicos desse período, prevaleceram análises sobre a intermediação de interesses no processo decisório e sobre características do sistema de proteção social no Brasil. Os estudos setoriais, por sua vez, tinham como eixo principal análises empíricas a partir de uma perspectiva crítica, orientadas para a busca de alternativas ao padrão centralizado e excludente das políticas públicas no período autoritário.

Se a democratização favoreceu um processo embrionário de institucionalização do campo nos anos 1980 e 1990, a expansão da produção sobre políticas públicas ocorrida nos anos 2000 , sobretudo a partir de meados dessa década, também deve ser vista em relação ao contexto político-institucional então prevalecente no país. A (re)institucionalização do campo de política pública nesse momento foi favorecida por medidas governamentais voltadas à expansão do acesso à universidade e à expansão da formação na área pública, tanto na graduação como na pós-graduação, assim como pela criação de oportunidades de inserção de profissionais formados em Política Pública, Administração Pública, Gestão de Política Pública e áreas correlatas. Também houve nesse período apoio à expansão da produção docente 
e discente, com impactos sobre o campo de política pública e sobre o campo de públicas que então se institucionaliza. A centralidade que as políticas públicas assumiram na agenda societária e governamental repercutiu sobre essa produção, que cresceu em ritmo superior à expansão da produção sobre outros temas.

O aumento da produção não alterou a tendência de fragmentação do campo e a predominância de estudos setoriais descritivos. Mas foi também acompanhado pelo reforço da vertente que se volta ao entendimento do processo de produção das políticas. Essa vertente contribuiu para a (re)institucionalização do campo ao possibilitar a constituição de um "core" de interpretação e debate teórico que transcende políticas setoriais. Nessa tradição, observa-se um deslocamento de estudos centrados no processo decisório (na formulação) para estudos sobre a formação da agenda e sobre a implementação. Quanto aos referenciais teóricos, destaca-se a presença do neoinstitucionalismo, em especial do neoinstitucionalismo histórico. A abordagem cognitiva que enfatiza o papel das ideias e do conhecimento no processo das políticas públicas também está presente, sendo mobilizadas contribuições de ao menos duas das vertentes que integram essa abordagem, segundo a classificação proposta por Sabatier e Schlager (2000): a vertente moderada e a maximalista.

A literatura nacional, desde o início do século 21 tem incorporado a complexidade que caracteriza o processo de produção das políticas, marcado pela presença de múltiplos atores - governamentais e não governamentais. Assim, temas como coordenação e cooperação, relações intergovernamentais e federalismo, capacidades estatais, papel de burocratas de diferentes escalões e novos arranjos institucionais participativos marcam essa produção recente. Embora a explicitação da noção de wicked problems seja relativamente pouco frequente, a produção das últimas décadas mobiliza conceitos e abordagens que se desenvolveram a partir do reconhecimento da complexidade. Os conceitos de rede de políticas, de comunidade de política, de comunidade epistêmica, de coalizão de defesa e o de governança são alguns dos que estão presentes na literatura brasileira recente, apreendendo a presença de múltiplos atores, estatais e não estatais e uma participação não hierárquica.

Num outro eixo, observa-se que a literatura tem sido capaz de incorporar a discussão de questões que emergem na agenda societária e na governamental, com destaque a temas transversais e à temática de direitos. Assim, as pesquisas e a produção se voltam para temas como meio ambiente e sustentabilidade, mobilidade urbana, segurança pública, pobreza e desigualdade, e para políticas voltadas a essas questões, com diferentes recortes empíricos. E passam a ser estudadas políticas para a juventude, para mulheres, para LGBTTs, para 
indígenas, e políticas de combate à desigualdade racial. Boa parte dessas temáticas é abordada a partir de novas abordagens teóricas, que se baseiam no reconhecimento da complexidade dos problemas públicos e do processo de produção das políticas, envolvendo estudos sobre multidimensionalidade, abordagem integral, intersetorialidade e transversalidade.

A trajetória do campo, apreendida na perspectiva da produção de estudos sobre políticas, revela, assim, que, apesar da tendência à fragmentação e à dispersão, é possível identificar um núcleo identitário que envolve a discussão densa de temas e problemas públicos relevantes, a partir de abordagens teóricas contemporâneas, que resultam do diálogo com a literatura internacional. Há, na produção brasileira sobre políticas públicas, uma dupla imersão: de um lado, na realidade brasileira e nos problemas públicos presentes na agenda societária e governamental, e, de outro, no campo de política pública no plano internacional, por meio do contato com teorias contemporâneas.

Em relação aos desafios que hoje se colocam ao campo, em especial à produção sobre políticas públicas, identifica-se um primeiro grupo que emerge da análise da trajetória dessa produção. Um primeiro desafio consiste no reforço de iniciativas que propiciem espaços de troca e discussão entre diferentes disciplinas. Reconhecida a característica fragmentária da produção, é possível, no entanto, fortalecer um núcleo identitário, o que requer um denominador comum "para além do objeto". Esse núcleo identitário supõe o reconhecimento da complexidade dos problemas públicos e do processo de política e requer uma abordagem que se beneficie da contribuição teórica e metodológica de diversas disciplinas. O núcleo identitário requer, além disso, uma densidade analítica que propicie ir além de estudos de casos descritivos setoriais. Embora a tarefa tenha sido iniciada, é preciso prosseguir nessa direção.

Um segundo desafio consiste em um esforço de aproximação entre os estudos de políticas públicas e as contribuições de caráter normativo e orientadas para a prática - na linha da policy analysis. Isso implica, de um lado, reforçar a conexão dos estudos gerados pela academia com problemas públicos relevantes, ancorados na agenda societária. E, de outro, buscar explicitar, em estudos aplicados de caráter normativo, seus pressupostos valorativos.

Um terceiro desafio consiste em gerar um conhecimento capaz de contribuir analiticamente para o processo de política pública contemporâneo, marcado pela existência de controvérsias relativas à própria definição do problema público e às alternativas de política, tal como propõe a vertente cognitiva de corte interpretativista e deliberativo. 
E, finalmente, um último desafio consiste na reflexão sobre os impactos da crise econômica e político-institucional dos últimos anos sobre o próprio campo. De um lado, sobre as condições de sua institucionalização. Essa institucionalização foi favorecida, como visto, pela expansão da formação em Política Pública, em Administração Pública e em áreas correlatas, por um lado, e pelo estímulo à produção acadêmica na área, por outro. Tais condições favoráveis estão ameaçadas pelo ambiente de crise, no contexto dos impactos já sentidos pela universidade e pela área de pesquisa como um todo, nos últimos anos. De outro lado, será preciso refletir analiticamente sobre as mudanças que a conjuntura de crise tende a impor às próprias políticas públicas, o "objeto singular" do campo. Mudanças já vêm ocorrendo sob o impacto de algumas medidas governamentais recentes, dentre as quais se destaca a EC 95, de 2016, que estabelece um teto para os gastos públicos por um período de 20 anos. É possível também que mudanças de governo a partir das eleições de 2018 conduzam a inflexões não apenas na agenda governamental, mas também na forma como os problemas públicos são definidos e na seleção de alternativas, tanto do ponto de vista do conteúdo das políticas como na forma com que são formuladas e implementadas. Os pesquisadores do campo, no Brasil, terão como um dos principais desafios refletir sobre essas mudanças, reconhecendo, inspirados pela literatura internacional recente, que os problemas públicos são "wicked problems" que envolvem processos marcados pela controvérsia. E diante de problemas complexos, marcados pela controvérsia em relação à própria definição e à natureza do problema público e pela disputa em relação a alternativas, será importante que a pesquisa se oriente por referenciais capazes de apreender essa complexidade e de contribuir para a busca de saídas baseadas na argumentação.

\section{Referências bibliográficas}

ABRUClo, Fernando Luiz. A Coordenação federativa no Brasil: a experiência do período FHC e os desafios do governo Lula. Revista de Sociologia Política, Curitiba, v. 24, p. 41-67, 2005.

ALLISON, Graham. Emergence of schools of public policy. In: Moran, Michael; ReIN, Martin; GoodIn, Robert F. (Eds.). The Oxford handbook of public policy. Nova York: Oxford University Press, 2008. p. 58-79.

ANDRADE, Jackeline Amantino de. Redes de atores: uma nova forma de gestão das políticas públicas no Brasil? Gestão e Regionalidade, n. 64, p. 52-66, 2006.

ARRETCHE, Marta. Democracia, federalismo e centralização no Brasil. Rio de Janeiro: Editora FGV; Editora Fiocruz, 2012. p. 145-173.

ARRETCHE, Marta. Dossiê agenda de pesquisa em políticas públicas. Revista Brasileira de Ciências Sociais, v. 18, n. 51. p. 7-9, 2003. 
Baumgartner, Frank.; Jones, Bryan D.; Mortensen; Peter B. Punctuated equilibrium theory: explaining stability and change. In: SABATIER, Paul; WEIBLE, Christopher m. (Eds.). The policy process. 3. ed. Westview: Westvies Press, 1999. p. 59-104.

BICHIR, Renata. Novos instrumentos de coordenação federativa: reflexões a partir do Programa Bolsa Família. Revista Brasileira de Políticas Públicas e Internacionais, v. 1, n. 1, p. 49-78, 2016.

BouRdieu, Pierre. Le champ scientifique. Actes de la recherche en sciences sociales, v. 2, n. 2-3, p. 88-104, 1976.

BRASIL Felipe; CAPELLA, Ana Claudia. Subsistemas, comunidades e redes: articulando ideias e interesses na formulação de políticas públicas. Revista do Serviço Público, v. 66, n. 3, p. 449-474, 2015.

CAPella, Ana C. N.; SoAres, Alessandra G.; Brasil, Felipe G. Pesquisa em políticas públicas no Brasil: um mapeamento da aplicação de modelos internacionais recentes na literatura nacional. In: Encontro da ABCP, 9., 2014 Brasília. Anais eletrônicos. Brasília: Associação Brasileira de Ciência Política, 2014. Disponível em: <http:// www.encontroabcp2014.cienciapolitica.org. br/resources/anais/14/1403738847_ ARQUIVO_ABCP_final.pdf. Acesso em: 14 abr. 2015.

Bueno, Luciano. Controle de armas: um estudo comparativo de políticas públicas entre Grã-Bretanha, EUA, Canadá, Austrália e Brasil. Dissertação apresentada ao Curso de Pós Graduação em Administração Pública e Governo da FGV-EAESP. São Paulo, FGV-EAESP, 2001.

CAPella, Ana Claudia. Perspectivas teóricas sobre o processo de formulação de políticas públicas. In: Hochman, Gilberto; ARretCHe, Marta; MARQUeS, Eduardo (Orgs.). Políticas públicas no Brasil. Rio de Janeiro: Editora Fiocruz, 2008. p. 87-124. CAPElLA, Ana Claudia; SOARES, Alessandra Guimarães; BrASIL, Felipe Gonçalves. Pesquisa em políticas públicas no Brasil: um mapeamento da aplicação de modelos internacionais recentes na literatura nacional. In: ENCONTRO DA ABCP, 9., 2014, Brasília, DF. Anais... Brasília: ABCP, 2014.

CASTRO, Camila Moreira. Public hearings as a tool to improve participation in regulatory policies: case study of the National Agency of Electric Energy. Revista de Administração Pública, v. 47, n. 5, p. 1069-1087, 2013.

COHEN, M.; MARCH, J.; OLSEN, J. A garbage can model of organizational choice. Administrative Science quarterly, 17, n. 1, p.1-25, 1972.

CORTES, Soraya. Sociologia e políticas públicas. In: MARQUES, Eduardo; FARIA, Carlos A. P. de (Orgs.). A política pública como campo multidisciplinar. São Paulo: Editora Unesp; Rio de Janeiro: Editora Fiocruz, 2013. p. 47-68.

CORTES, Soraya. Viabilizando a participação em conselhos de política pública: arcabouço institucional, organização do movimento popular e policy communities. In: Hochman, Gilberto; ArRetche, Marta; Marques, Eduardo (Orgs.). Políticas públicas no Brasil. Rio de Janeiro: Fiocruz, 2007. p. 125-144.

COSTA, Bruno Lazzarotti Diniz; BRonzo, Carla. Intersetorialidade no enfrentamento da pobreza: o papel da implementação e da gestão. In: FARIA, Carlos Aurélio Pimenta 
de (Org.). Implementação de políticas públicas: teoria e prática. Belo Horizonte: PUC Minas, 2012. p. 50-81.

COSTA, Nilson Rosário da. Comunidade epistêmica e a formação da reforma sanitária no Brasil. Physis Revista de Saúde Coletiva, Rio de Janeiro, v. 24, n. 3, p. 809-829, 2014.

CUNILL-GraU, Núria. La intersetorialidad em las nuevas políticas sociales: um acercamiento analítico-conceptual. Gestión y Políticas Públicas, v. 23, n. 1, p. 5-46, 2014.

DAGNino, Evelina (Org.). Sociedade civil e espaços públicos no Brasil. São Paulo: Paz e Terra, 2002.

DRAIBE, Sonia Miriam. Brasil: o sistema de proteção social e suas transformações recentes. Santiago, Chile: Cepal, 1983.

DRÈZE, Jean; SEN, Amartya. Hunger and public action. Oxford: Oxford University Press, 1997 (primeira edição: 1989).

FADUL, Élvia et al. Administração pública no Brasil: reflexões sobre o campo de saber a partir da Divisão Acadêmica da Associação Nacional de Pós-Graduação e Pesquisa em Administração (2009-2013). Revista de Administração Pública, v. 48, n. 5, p. 1329-1354, 2014.

FARAH, Marta F. S. Administração pública e políticas públicas. Rev. Adm. Pública, v. 45, n. 3, p. 813-836, 2011.

FARAH, Marta F. S. Análise de políticas públicas no Brasil: de uma prática não nomeada à institucionalização do "campo de públicas". Revista de Administração Pública, v. 50, n. 6, p. 959-979, 2016.

FARAH, Marta F. S. Formação em política pública no Brasil. Das iniciativas pioneiras dos anos 60 à institucionalização do "campo de públicas". Estudios políticos, v. 49, p. 192-215, 2016b.

FARAH, Marta Ferreira Santos et al. Gênero e política pública: panorama da produção acadêmica no Brasil (1983-2015). Cadernos Ebape, v. 16, n. 3, p. 428-443, jul./set. 2018.

FARIA, Carlos Aurélio Pimenta de. Ideias, conhecimento e políticas públicas: um inventário sucinto das principais vertentes analíticas recentes. Revista Brasileira de Ciências Sociais, v. 18, n. 51, p. 21-29, 2003.

FARIA, Carlos Aurélio Pimenta de. Implementação: ainda o "elo perdido" da análise de políticas públicas no Brasil? In: FARIA, Carlos Aurélio Pimenta de. Implementação de políticas públicas: teoria e prática. Belo Horizonte: Ed. PUC Minas, 2012a. p. 123153.

FARIA, Carlos Aurélio Pimenta de. Implementação de políticas públicas: teoria e prática. Belo Horizonte: Ed. PUC Minas, 2012b.

FISCHER, Frank. Beyond Empiricism: policy inquiry in post positivist perspective. Policy Studies Journal, v. 26. n. 1, p. 129-146, 1998.

FISCHER, Frank; FORESTER, John (eds.). The argumentative turn in policy analysis and planning. 2. ed. Durham: Duke University Press, 1996. 
FISCHER, Frank; MILLER, Gerald J.; SIDNEY, Mara (Eds.). Handbook of public policy analysis: theory, politics, and methods. Boca Raton: CRC Press, Taylor and Francis, 2007.

FISCHER, Tânia. Administração pública como área de conhecimento e ensino: a trajetória brasileira. Revista de Administração de Empresas, v. 24, n. 4, p. 278-288, 1984.

FREDERICKSON, H. George. John Gaus Lecture - The repositioning of American Public Administration. PS: Political Science and Politics, v. 32, n. 4, p. 701-

711, dec. 1999.

FuKs, Mario. Definição da agenda, debate público e problemas sociais: uma perspectiva argumentativa da dinâmica do conflito social. In: Bib, n.49, p. 79-94, 2000.

GraU-SOlÉS, Marc; Í̃̃IGUEZ-RUEdA, Lupicinio; SUBIRATS, Joan. ¿Cómo gobernar la complejidad? Invitación a una gobernanza urbana híbrida y relacional. Athenea Digital, v. 11, n.1, p. 63-84, 2011.

HAAS, Peter M. Introduction: epistemic communities and international policy coordination. International Organization, v. 46, n. 1, p. 1-35, 1992.

HAJER, Maarten A. Discourse coalitions and the institutionalization of practice: the case of acid rain in Britain. In: FISCHER, Frank; FORESTER, John (Eds.). The argumentative turn in policy analysis and planning. Durham: Duke University Press, 1996. p. 43-75

HALL, Peter A. Policy paradigms, social learning, and the State: the case of economic policymaking in Britain. Comparative Politics, v. 25, n. 3, p. 275-296, 1993.

HEAD, Brian W. Wicked problems in public policy. Public Policy, v. 3, n. 2, p. 101-118, 2008.

HECLO, Hugh. Issue networks and the executive establishment. In: MCCooL, Daniel C. (Ed.). Public policy theories, models, and concepts: an anthology. Prentice Hall, 1995. p. 268-287. (Artigo original de 1978)

HenRY, Nicholas. Paradigms of Public Administration. Public Administration Review, v. 35, n. 4, p. 378-386, 1975.

JORDAN, Grant. Policy community realism versus 'new' institutionalist ambiguity. Political Studies, n. 38, 470-484, 1990.

JOBERT, Bruno; MulLer, Pierre. L'Etat en action: politique publiques et corporatismes. Presses Universitaires de France, 1987.

KIngdon, John W. Agenda setting. In: Theodoulou, Stella Z.; CAHN, Matthew A. Public policy: the essential readings. Upper Saddle River, NJ: Prentice Hall, 1995. p. 105-112.

LASWELL, Harold D. The emerging conception of the Policy Sciences. Policy Sciences, v. 1, p. 3-14, 1970.

Lindblom, Charles E. The science of muddling through. Public Administration Review, v. 19, n. 2, p. 79-88, 1959. 
LIMA JÚNIOR, Olavo Brasil de; SANTOS, Wanderley Guilherme dos. Esquema geral para a análise de políticas públicas: uma proposta preliminar. Revista de Administração Pública. v. 10, n. 2, 1976.

LIPSKY, Michael. Street-level bureaucracy: dilemmas of the individual in public services. New York: Russell Sage Foundation, 2010 ( $1^{\text {st }}$ edition, 1980).

LOTTA, Gabriela S.; PAVEZ, Thais R. Agentes de implementação: mediação, dinâmicas e estruturas relacionais. Cadernos Gestão Pública e Cidadania, v. 15, n. 56, p. 109125, 2010.

LUKIC, Melina Rocha; TOMAZINI, Carla. Abordagens cognitivas na análise de política públicas na América Latina: um novo olhar sobre velhas questões? In: ENCONTRO DA ABCP, 9., 2014, Brasília, DF. Anais... Brasília: ABCP, 2014.

MARQUES, Eduardo. Redes sociais e instituições na construção do Estado e da sua permeabilidade. Revista Brasileira de Ciências Sociais, v. 14, n. 41, p. 45-67, 1999.

MARQUES, Eduardo. State institutions, power, and social networks in Brazilian urban policies. Latin American Research Review, v. 47, n. 2, p. 27-50, 2012.

MARques, Eduardo. As políticas públicas na Ciência Política. In: MARquES, Eduardo; FARIA, Carlos A. P. de (Orgs.). A política pública como campo multidisciplinar. São Paulo: Editora Unesp; Rio de Janeiro: Editora Fiocruz, 2013. p. 23-47.

Melo, Marcus A. Estado, governo e políticas públicas. In: Miceli, Sergio (Org.). $O$ que ler na Ciência Social brasileira (1970-1995). Ciência Política, Vol.III. São Paulo: Ed. Sumaré; Brasília: Anpocs/Capes, 1999. p. 59-100.

MULLER, Pierre. L'analyse cognitive des politiques publiques: vers une sociologie politique de l'action publique. Revue française de science politique, v. 50, n. 2, p. 189-208, 2000.

MULLER, Pierre. Réferentiél. In: Dictionnaire des politiques publiques. Paris: Presses de Sciences Po (P.F.N.S.P.), 2010 (3 éd.). p. 555-562.

NEPP/UNICAMP. 1986. Brasil 1985: Relatório sobre a situação social do País. Campinas, 2 vols.

OSPINA-BozzI, Sonia M. La administración pública como "comunidad discursiva": algunas lecciones del caso estadounidense para América Latina. Reforma y Democracia, n. 10, p. 85-112, 1998.

PACHECO, Regina Silvia. Administração Pública nas revistas especializadas - Brasil, 1995-2002. Revista de Administração de Empresas, v. 43, n. 4, p. 63-71, 2003.

Palavras do diretor. Revista de Administração Pública, v. 10, n, 2, p. 3-4, 1976.

PAlIER, Bruno; SUREL, Yves. Les "trois I" et l'analyse de l'État en action. Revue française de science politique, v. 55, n. 1, p. 7-32, 2005.

PAPA, Fernanda de Carvalho. Transversalidade e políticas públicas para mulheres no Brasil: percursos de uma pré-política. Dissertação apresentada ao Programa de Mestrado em Administração Pública e Governo da FGV-EAESP. São Paulo, 2012.

PEREIRA, Maria Cecília Gomes. Água e convivência com o semiárido: múltiplas águas, distribuições e realidades. Tese de doutorado em Administração Pública e Governo. FGV/EAESP. 2016. 
Peters, Guy; Pierre, Jon. Multi-level governance: a view from the garbage can. Manchester Papers in politics: EPRU series, 1, [s.p.], 2002.

Petineluı, Viviane. As conferências públicas nacionais e a formação da agenda de políticas públicas do Governo Federal (2003-2010). Opinião Pública, Campinas, v. 17, n. 1, p. 228-250, junho 2011.

PIRES, Roberto Rocha C. Intersetorialidade, arranjos institucionais e instrumentos da ação pública. In: MACEDo, Juliana Macedo; XEREZ, Flávia Helena Saraiva; LOFRANO, Rodrigo (Orgs.). Intersetorialidade nas políticas sociais: perspectivas a partir do programa Bolsa Família. Cadernos de Estudos Desenvolvimento Social em Debate, n. 26, p. 67-80, 2016.

POLLACK, Mark A.; HAFNeR-BURTON, Emile. Mainstreaming gender in the European Union. Journal of European Public Policy, v. 7, n. 3, Special Issue, p. 432- 456, 2000. PRESSMAN, L.; WILDAVSKY, Aaron. Implementation: how great expectations in Washington are dashed in Oakland. 3. ed. Berkley and Los Angeles: University of California Press, 1984. (first edition, 1973).

RADIN, Beryl A. Beyond Machiavelli: Policy Analysis comes of age. Washington D.C.: Georgetown University Press, 2000.

REIN, Martin. Reframing problematic policies. The oxford handbook of Public Policy. In: Moran, Michael; ReIN, Martin; Goodin, Robert F. (Eds.) The Oxford Handbook of Public Policy. New York: Oxford University Press, 2008. p. 389-409.

REIN, Martin; SCHON, Donald. Frame-critical policy analysis and frame-reflective policy practice. Knowledge and Policy: The International Journal of Knowledge Transfer and Utilization, v. 9, n. 1, p. 85-104, 1996.

REINACH, Sofia. A "transversalidade" brasileira: uma construção própria que vai além das influências internacionais. In: ENCONTRO FAZENDO GÊNERO, 10., 16 a 20 de set. 2013, Florianópolis. Anais... Florianópolis: Universidade Federal de Santa Catarina, 2013.

REIS, Fábio. Política e políticas. Revista de Administração Pública. v. 10, n. 2, p. 5263, 1976.

RHOdES, R. A. W. Policy network analysis. In: MoRAN, Michael; ReIN, Martin; Goodin, Robert E. (Eds.). The Oxford Handbook of public policy. New York: Oxford University Press, 2008. p. 425-448.

RitTeL, Horst W. J.; WebBeR, Melvin M. Dilemmas in a General Theory of Planning. Policy Sciences, v. 4, n. 2, p. 155-169, 1973.

ROE, Emery M. Narrative analysis for the policy analyst: a case study of the 19801982 Medfly Controversy in California. Journal of Policy Analysis and Management, v. 8, n. 2, p. 251- 273, 1989.

Roth Deubel, André-Noël. Políticas Públicas: formulación, implementación y evaluación. Bogotá: Ediciones Aurora, 2014.

SABATIER, Paul A. An advocacy coalition framework of policy change and the role of policy-oriented learning therein. Policy Sciences, v. 21, p. 129-168, 1988. 
SABATIER, Paul A. Toward better theories of the policy process. PS: Political Science and Politics, v. 24, n. 2, p. 147-156, 1991.

SABATIER, Paul A.; SCHLAger, Edella. Les approches cognitives des politiques publiques: perspectives américaines. Revue française de science politique, v. 50, n. 2, p. 209-234, 2000.

SIMIELLI, Lara Elena R. Coalizões em educação no Brasil: relação com o governo e influência sobre o Plano de Desenvolvimento da Educação (PDE). Revista de Administração Pública, v. 47, n. 3, p. 568-586, 2013.

SIMON, Herbert A. Theories of bounded rationality. In: MCGUIRE, C. E.; REDNER, Roy (Eds.). Decision and organization. Amsterdam: NorthOHolland Publishing Company, 1972. p. 161-176.

SKOCPOL, Theda. Bringing the State back in: strategies of analysis in current research. In: Evans, Peter; RueSCHEMEYER, Dietrich; SKOCPOL, Theda. Bringing the State back in. 7. ed. New York: Cambridge University Press, 1997. (1ㅇe edição de 1985)

SOUZA, Celina. "Estado do campo" da pesquisa em políticas públicas no Brasil. Revista Brasileira de Ciências Sociais, v. 18, n. 51, p. 15-20, 2003.

SouzA, Celina. Políticas públicas: uma revisão da literatura. Sociologias, Porto Alegre, ano 8, n. 16, p. 20-45, jul./dez. 2006.

SouzA, Luiz Ricardo de; SECCHI, Leonardo. A Política Científica e Tecnológica de Santa Catarina: análise a partir do modelo de coalizões de defesa. Revista de Administração Pública, v. 48, n. 4, p. 939-960, 2014.

SOUZA, Wanderson; FARAH, Marta Ferreira Santos. Concepções em disputa: ideias e discursos na constituição do campo e na formação das políticas de juventude no Brasil. In: ENCONTRO ANUAL DA ANPOCS - ASSOCIAÇÃo NACIONAL DE PÓs-GRADUAÇÃo E PESQUISA EM CIÊNCIAS SocIAIS, 41., 23 a 27 de out. 2017, Caxambu. Anais... Caxambu: ANPOCS, 2017.

SPINK, Peter K. Institutions, Civil Society and Social Capital: the dangers of the post Washington Consensus. In: INTERNATIONAL CONGRESS OF LATIN AMERICAN STUDIES Association (LASA), 6 a 7 de set. 2007, Montreal, Canadá. Anais... Montreal: LASA, 2007.

StATION, Elizabeth; WELNA, Christopher J. Da administração pública à participação democrática. In: OS 40 ANOS da Fundação Ford. Brooke, Nigel; Witoshynsky, Mary (Orgs.). São Paulo/Rio de Janeiro: EDUSP/Fundação Ford, 2002. p. 167-200.

SUBIRATS, Joan et al. Análisis y gestión de políticas públicas. Barcelona: Editorial Planeta, 2008.

TAYLOR, Rosemary C. R.; HALL, Peter A. As três versões do neo-institucionalismo. Lua Nova, v. 58, p. 193-223, 2003.

THÉRET, Bruno. As instituições entre as estruturas e as ações. Lua Nova, v. 58, p. 226-255, 2003.

TROJBICZ, Beni. Ideias e economia nas reformas das políticas públicas do setor de petróleo brasileiro: 1995 a 2010. Revista de Administração Pública, Rio de Janeiro, v. 51, n. 5, p. 767-787, 2017. 
Trottmann, Paula et al. A produção científica em Políticas Públicas no Brasil: descrição e análise de alguns resultados de uma investigação sobre a primeira década dos anos 2000. Revista de Discentes de Ciência Política da UFSCAR, v.5, n. 2, p. 223-253, 2017.

VAITSMAn, Jeni et al. (Ed.). Policy Analysis in Brazil. Bristol: Policy Press at University of Bristol, 2013.

VALLADARES, Lícia do P. Estudos recentes sobre a habitação no Brasil: resenha da literatura. In: VALLADARES, Lícia do P. (Org.). Repensando a habitação no Brasil. Rio de Janeiro: Zahar, 1981.

VeIGA, Laura da; BRonzo, Carla. Estratégias intersetoriais de gestão municipal de serviços de proteção social: a experiência de Belo Horizonte. Revista de Administração Pública, v. 48, n. 3, p. 595-620, 2014.

Velloso, João P. R. Depoimento. In: D’Araúso, Maria Celina; FARIAS, Ignez Cordeiro de; HIPPOLITo, Lucia (Orgs.). Ipea: 40 anos apontando caminhos. Depoimentos ao CPDOC, 2004, p. 21.

WAGENAAR, Hendrik. Meaning in action: interpretation and dialogue in policy analysis. New York: Routledge, 2015.

WAMPler, Brian; AVRItZer, Leonardo. Participatory publics: civil society and new institutions in democratic Brazil. Comparative Politics, v. 36, n. 3, p. 291-312, 2004.

\section{Marta Ferreira Santos Farah}

Doutora em Sociologia pela Universidade de São Paulo (USP). Atualmente é professora titular da Escola de Administração de Empresas de São Paulo, da Fundação Getúlio Vargas (FGV). Contato: marta.farah@fgv.br 
RSP 